\title{
De La Habana a Veracruz y de Veracruz a la ciudad de México ${ }^{1}$
}

Edwar B. Tylor

\section{Introducción}

En 1856 México recibió una visita distinguida de un personaje británico. Bueno, México apenas había surgido todavía como una república independiente -después de 300 años de existencia como colonia en el imperio español-y definitivamente no se encontraba capacitado para recibir visitas distinguidas.

El personaje británico en cuestión tampoco no había alcanzado todavía la fama como para llamar la atención. Se trata de un tal Edward Burnett Tylor, el futuro fundador de la antropología moderna, una disciplina que se conocería como "la ciencia de Tylor". Él era todavía un joven mocoso de la nueva burguesía mercantil en Inglaterra, que había buscado una de las regiones más transparentes en el mundo para recuperar su salud después de una serie de ataques de asma.

$\mathrm{Su}$ viaje había empezado en Cuba, donde se había juntado con Henry Christy, un banquero que viajaba en su tiempo libre con el objetivo de comprar piezas arqueológicas, y el 8 de marzo de 1856 los dos caballeros abandonaron Cuba para llegar primero a Sisal en Yucatán y luego a Veracruz.

Lo primero que comenta Tylor, al salir de Veracruz en "una diligencia fuerte, construida en los Estados Unidos, con cupo para nueve adentro", es la seguridad que hasta hoy sigue siendo una preocupación mayor: "Las diligencias corrían de nuevo, después de que su tráfico se había interrumpido durante algunos meses debido al estado de alboroto en el país; solamente evitaban a Puebla que todavía se encontraba bajo sitio. Estábamos ansiosos por partir inmediatamente, pero el Señor Christie señaló sagazmente que los ladrones probablemente sabrían de la llegada del vapor, por lo que con seguridad asaltarían a la primera diligencia, y nos decidimos por la siguiente que saldría un día después".

Los ferrocarriles en México atraen la atención de Tylor: "iniciamos nuestro viaje siendo jalados a lo largo de las vías del ferrocarril -cuya construcción fue empezada con gran ímpetu hace algún tiempo, pero solamente avanzó quince kilómetros en el camino hacia la capital, luego nunca ha vuelto a moverse", como también lo habían hecho en Cuba, donde "el ferrocarril que nos llevó de La Habana a Batabanó poseía características muy peculiares. Parte del tramo se encontraba entre dos paredes de selva tropical. Los higueras indios enviaron desde cada ramo sus tentáculos parecidos a suaves hilos que se insertaron

1 Traducción e introducción de Leif Korsbaek. E-mail: 1korsbaek@yahoo.com.mx 
en la tierra y chupaba aún más agua. Se apretaron las acacias y las mimosas, las ceibas y mahaguas y otras innumerables maderas finas; mientras que las epifites se percharon desde cada ramo, y las lianas convirtieron la selva en una masa compacta de vegetación a través de la cual ningún pájaro lograría volar. Podíamos agarrar los hilos de los convulvulus con nuestros bastones, a la medida que el tren se movía a través de la selva. Ocasionalmente pasamos por un pantano donde crecían manojos de palmeras coronadas de penachos de hojas puntiagudas, o avistamos por un momento un grupo de palmeras reales sobre una extensión de terreno elevado"'.

Tylor todavía no es antropólogo, pero ya piensa en la antropología: "Las últimas dos teorías tienen hoy sus adeptos. Por crudas que sean estas ideas, uno siente mucha simpatía por la primera investigación que llevó a la gente a pensar seriamente en el origen de las razas y echaron los fundamentos de la ciencia de la etnología". "Cuando los españoles llegaron a esos países, y tan pronto como tuvieron tiempo para preguntarse cuál podría ser el origen de esa gente que habían encontrado allá, inmediatamente llegó la respuesta: "la tribu perdida de Israel, por supuesto". Y mirando a estos hombres serios y taciturnos, con su tez morena, ojos brillantes y nariz llamativamente aguileña, no parece extraño que esta idea hubiera sido generalmente aceptada, tomando en cuenta los conocimientos al respecto en aquellos días. Los ingleses encontramos a las diez tribus en los pieles rojas en el norte, autores judíos han escrito libros en hebreo para su propio pueblo para informarles que el resto de su raza había sido encontrado en las montañas de Chile, guardando rasgos inconfundibles de su origen y conversando perfectamente en hebreo, y recientemente han aparecido en las costas del Mar Caspio, juntos y convertidos al cristianismo.

Si consideramos la obra de Tylor como una especie de etnografía de tiempo libre (así como lo sugirió Céléstin Bouglé a Lévi-Strauss antes de mandarlo a Sao Paolo para enseñar sociología, como cuenta este en su "Tristes Trópicos"), entonces hay varios detalles que merecen nuestra atención.

La narración etnográfica es, a fin de cuenta, narración, y como tal tiene que respetar algunas de las reglas de la transmisión literaria. Señala Gregory Bateson en el primer capítulo de su gran monografía "Naven", acerca de la exposición etnográfica, que "se puede intentar mediante el uso de uno de dos métodos: por medio de técnicas científicas o artísticas. Por el lado artístico, tenemos las obras de un pequeño puñado de hombres que no solamente han sido grandes viajeros y observadores, sino también escritores de gran sensibilidad, hombres tales como Charles Doughty; y también tenemos representaciones espléndidas de nuestra propia cultura en novelas como las de Jane Austin o John Galsworthy. Por el lado científico, tenemos las monografías detalladas y monumentales acerca de un pequeño número de pueblos, y recientemente las obras de Radcliffe-Brown, Malinowski y la Escuela Funcionalista".

En esta narración se tiene que hacer uso del ritmo. El ritmo cambia constantemente en la relación de Tylor, y podemos distinguir por lo menos dos diferentes cadencias y temporalidades en el material presentado: en un momento está hablando de la configuración del paisaje y nos da toda una conferencia científica acerca de las cualidades geológicas de las regiones a través de las cuales se mueven nuestros dos viajeros, y en el siguiente momento nos encontramos en una sala comedor en una casa en alguna comunidad donde la acción se desarrolla rápidamente. Tenemos la necesidad de presentar las dos temporalidades (y tal vez más) en cualquier etnografía.

Uno de los principales vicios de la Inglaterra victoriana era probablemente el etnocentrismo, vicio que fue bautizado a principios del siglo XX por William Graham

2 La cita es del Capítulo I del mismo libro de Tylor. 
Sumner en su "Folkways" en 1912, pero que ya existía plenamente antes de su bautizo. La más contundente ilustración de este etnocentrismo sería probablemente el chiste popular que se contaba acerca de James Frazer, autor de numerosas obras acerca de los salvajes: Frazer encontró a un conocido en la calle, en Londres, y éste le preguntó a Frazer si alguna vez había visto en carne y hueso a uno de estos salvajes acerca de los cuales tantos volúmenes había escrito, y contestó Frazer sin titubeo que “no, y Dios me libre”. En este contexto, y pensando específicamente en el texto de Tylor, podemos plantearnos la pregunta, si la ironía, por fina que sea, es un tono adecuado para un texto etnográfico $\mathrm{y}$, más precisamente, ¿cuál es la relación entre la ironía y el etnocentrismo?

En 1856, Tylor todavía no había decidido hacerse antropólogo, y su expedición es al mismo tiempo un viaje de reconvalecencia y uno de estos viajes de educación(Bildungsreisen, en alemán) que formaban parte de los jóvenes de la burguesía para que conocieran el gran mundo. Pero ya estamos a punto de distanciarnos de la "antropología de gabinete" que representa tan contundentemente James Frazer y acercarnos a la antropología moderna que se basa en el trabajo de campo, acercarnos a los salvajes sin este miedo que es la raíz del etnocentrismo y la discriminación. En este sentido, podemos ver en la relación de Tylor el primer acercamiento al trabajo de campo que posteriormente será tan importante en la antropología. El viaje ya no es turismo, pero todavía no es trabajo de campo sistemático, es algo intermedio. Desde este punto de partida, a Tylor y sus seguidores profesionales les toca alejarse del etnocentrismo que era parte orgánica de la antropología de gabinete.

El texto que sigue es la traducción del capítulo dos del libro de Edward Burnett Tylor, Anahuac, or Mexico and The Mexicans, Ancient and Modern, que fue publicado en Londres en 1861 por la editorial Longman, Longman, Longman \& Greene's, y es un adelanto de la traducción de los doce capítulos del texto entero. Como se ve, el capítulo aquí traducido describe la llegada de Tylor a Veracruz y su viaje a través del paisaje veracruzano rumbo a la capital de la joven República en 1856.

Solamente cabe señalar que el texto es ameno, pues carece de un pesado aparato de referencias bibliográficas.

\section{Capítulo II: De La Habana a Veracruz y de Veracruz a México ${ }^{3}$}

El ocho de marzo abordamos el vapor "Méjico", un barco construido en los Estados Unidos. Todavía viajaban en él los ingenieros norteamericanos, pero en todos los otros aspectos había sido convertido en un barco español, y ahora se encontraba atracado en el puerto de La Habana con rumbo a Veracruz, haciendo escala en Sisal, Yucatán. A las ocho levantamos ancla y el piloto nos guió a través del paso estrecho que sale del puerto pasando cerca del Castillo de El Moro y la fortaleza de Cabañas. La vista de sus rampas y baterías causó todo un alboroto entre los pasajeros españoles que creen firmemente que son impregnables.

Entre los demás pasajeros se encontraba una compañía de comediantes de quinta categoría que iban a Mérida por vía de Sisal. Alrededor de ellos no había nada interesante. La gente de teatro y la jerga de su profesión varían poco a través de todo el mundo civilizado. Había también dos o tres comerciantes españoles y franceses que regresaban a México. No hablaban de otra cosa que de los peligros de la carretera, y con razón: todos serían asaltados antes de llegar a su casa. Varios de los demás eran jugadores y aventureros políticos, o pertenecían al mismo tiempo a ambas categorías, como frecuentemente sucede en estas partes del mundo. España y las repúblicas latinoamericanas producen en gran número estas

3 Traducción de Leif Korsbaek (ENAH-INAH). La traducción ha sido revisada por Marcela Barrios Luna, César Huerta Ríos y Sergio Ricco Monge. 
gentes, exactamente como Missouri produce bandidos fronterizos y sus cómplices. Pero el rufián es un tipo simpático en comparación con estos villanos bien vestidos y corteses que le hubieran ofrecido a Fielding uno o dos consejos que habría apreciado para la elaboración de las figuras del señor Jonathan Wild y su amigo el conde.

La mañana del tercer día de nuestro viaje alcanzamos Sisal y, en cuanto el capitán nos dio permiso, bajamos a una canoa que parecía una caja plana de madera. Hay que mencionar que el capitán era catalán, un tipo de mal humor, que no se esforzó por esconder su desprecio por nuestras mentes inquisitivas y nuestras pesquisas, que parecía divertirse frustrándolas. Sisal sería el único lugar que conoceríamos en Yucatán, un país cuyo nombre se asocia con las ideas de frutas tropicales, donde uno tiene que abrirse paso en la selva a machetazos y de enormes ruinas de templos y ciudades abandonadas, cubiertas de una densa vegetación. Pero de eso no había nada. Sisal es un pequeño pueblo miserable colocado en la costa, con un gran saladar en su hinterland. Tiene un pequeño muelle, que justifica su título de puerto, y allí se encontraban dos o tres barcos mercantes, cargando madera (el principal producto del distrito), caoba, cueros y pieles de venado. Nos sorprendió encontrar aquí pieles de venado, pero cuando investigamos el asunto, aprendimos que gran número de venados, así como ganado bovino, habitan los distritos escasamente poblados alrededor de las costas del Golfo de México, y que éstos prosperan a pesar del clima ardiente, si exceptuamos los años de sequía que matan a los animales por miles.

Examinamos, con la mayor precisión que nos permitieran las condiciones, un sólo artículo de exportación: los habitantes indígenas. Allí está, en cada aspecto, el perfecto artículo para el comercio: morenos, indefensos, fuertes, saludables y trabajadores, y las radas y los manglares de Cuba se encuentran solamente a una distancia de tres días de navegación. Las plantaciones y las minas, que requieren cien mil hombres para ponerlos a trabajar de lleno, y que pueden absorber a indígenas, chinos y negros sin distinción -cualquier cosa que tenga la tez morena y que sea posible hacerla trabajar- aceptarían a esos yucatecos en la cantidad que fuera, y les pagarían bien. Y una vez que se encuentren en una plantación de azúcar o adentro de una mina, cuando ya se haya hecho su registro fingido y el gobernador haya recibido su onza de oro por cada uno de ellos, dejándolos pasar, y sus subordinados su tajada, entonces ¿quién los sacaría de nuevo o quién siquiera los encontraría?

La idea se me ocurrió cuando estábamos sentados mirando a los indígenas que cargaban y descargaban sus lanchas, y trabamos en conversación con un español inteligente. Según él, ya habían llevado indígenas a Cuba, pero solamente unos pocos y ninguno desde 1854, cuando dos ingleses que habían llegado a la costa en una galeta con la intención de comerciar, lograron salirse con una carga de setenta y dos indígenas. Pero cuando los sorprendió un viento fuerte tuvieron que buscar puerto - de todos los lugares posibles en el mundo- en la parte británica de Belice. Allí alguien se dio cuenta del carácter de su carga, el barco fue confiscado y los indígenas devueltos a Yucatán, y los dos aventureros fueron condenados a trabajo forzado, uno a cuatro años y el otro a dos años y medio. En un lugar donde la fatiga, el ejercicio y la guardia representan la muerte a un soldado europeo, eso sería con toda seguridad una manera de imponerles pena capital, lenta pero muy segura ${ }^{4}$.

Cuando los españoles llegaron a esos países y tan pronto como tuvieron tiempo para preguntarse, ¿cuál podría ser el origen de esa gente que habían encontrado allá? inmediatamente llegó la respuesta: "las tribus perdidas de Israel, por supuesto". Y mirando a

4 Sin embargo, hemos tenido noticias, en otro contexto, de una guerra que se está desarrollando en el interior del país entre los habitantes blancos y la población indígena y, aparentemente, el objetivo de los blancos es capturar a los indígenas y venderlos como esclavos a Cuba. 
estos hombres serios y taciturnos, con su tez morena, ojos brillantes y nariz llamativamente aguileña, no parece extraño que esta idea hubiera sido generalmente aceptada, tomando en cuenta los conocimientos al respecto en aquellos días. Los ingleses encontramos a las diez tribus en los pieles rojas, en el norte, autores judíos han escrito libros en hebreo para su propio pueblo a fin de informarles que el resto de su raza había sido encontrado en las montañas de Chile, guardando rasgos inconfundibles de su origen y conversando perfectamente en hebreo, y recientemente han aparecido en las costas del Mar Caspio, juntos y convertidos al cristianismo. Las últimas dos teorías tienen hoy sus adeptos. Por crudas que sean estas ideas, uno siente mucha simpatía por la primera investigación que llevó a la gente a pensar seriamente en el origen de las razas y echaron los fundamentos de la ciencia de la etnología.

Nuestro regreso al barco fue un asunto largo y tardado, pues un fuerte viento soplaba casi exactamente en contra de nosotros, y nuestra pesada embarcación tuvo que hacer vuelta tras vuelta antes de llegar al vapor. Flotaban grandes medusas esperando alguna presa y pasamos por grandes manchas de sargazo correoso, que se convertían en sogas largas. El termómetro nos mostró 84 grados Fahrenheit, cuando lo metimos al agua.

La madrugada del duodécimo día, cuando subimos a la cubierta, nos esperaba una vista grandiosa. Ninguna playa estaba a la vista, pero un pesado banco de nubes estaba parado en el horizonte, y en lo alto, encima de ellas, se veía el pico nevado de Orizaba, a una distancia de ciento cincuenta millas.

Antes del mediodía entramos al puerto de Veracruz. Vemos la pequeña isla y el fuerte de San Juan de Ulua frente al malecón y la Isla de los Sacrificios un poco más a la izquierda. Vemos una línea de muralla de la ciudad a lo largo del agua y arriba, los techos planos de las casas y las torres y cúpulas de muchas iglesias. Todo era gris, solamente interrumpido por las tejas españolas en los techos de las iglesias y una o dos banderas en el puerto. No se veía ni un pedazo de vegetación y los rayos del sol se nos abalanzaban.

Cuando nos habíamos instalado en la posada, discutimos las perspectivas de nuestro viaje a la capital. Las diligencias corrían de nuevo, después de que su tráfico se había interrumpido durante algunos meses debido al estado de alboroto en el país; solamente evitaban a Puebla que todavía se encontraba bajo sitio. Estábamos ansiosos por partir inmediatamente, pero el señor Christie señaló sagazmente que los ladrones probablemente sabrían de la llegada del vapor, por lo que con seguridad asaltarían a la primera diligencia, y nos decidimos por la siguiente que saldría un día después.

Fuimos bien recibidos por los comerciantes ingleses, para quienes mi acompañante tenía cartas de recomendación, y empezamos a averiguar cuál era el estado de las cosas en México.

En promedio, la Presidencia de México había cambiado cada ocho meses durante los últimos diez años, y don Ignacio Comonfort había accedido al oficio en el mes de diciembre pasado, al ser nominado su antecesor, el mulato general Álvarez, quien se había retirado a las provincias del sur con su ejército.

El presidente Comonfort, con la caja vacía y solamente un mínimo de poder político real, había sentido la necesidad de un gran esfuerzo para asegurar la popularidad de sí mismo y de su gobierno, por lo que había adoptado la política de atacar los fueros, los privilegios extraordinarios de las dos clases de sacerdotes y soldados, que se había hecho parte de la constitución, durante el régimen de los primeros virreyes, y con lo cual ni siquiera la guerra de independencia y la adopción de formas republicanas habían acabado. Ninguna de las dos clases es responsable ante los tribunales civiles, en caso de deudas u otras ofensas. El clero posee inmensas riquezas y tiene mucha influencia espiritual entre las clases más bajas. En 
el momento que descubrieron la disposición del nuevo Presidente, establecieron a un tal don Antonio Haro y Tamírez como presidente en rebeldía y lo establecieron en Puebla, la segunda ciudad de la república, donde abundan los sacerdotes y la influencia clerical no tiene límites. Al mismo tiempo, intentaron lanzar un pronunciamiento en la capital, pero el Presidente les ganó después de una breve lucha y mandó a todos sus soldados regulares a atacar Puebla. En el momento de nuestra llegada, el sitio de Puebla estaba en su apogeo, con diez mil soldados luchando bajo el mando de cuarenta y tres generales.

Cuando sea que suceda algo desagradable en México, es seguro que a Veracruz le toca su parte plenamente. Un mes antes de nuestra llegada, un tal Salcedo, quien era prisionero en el castillo de San Juan de Ulua, había discutido el asunto con la guarnición y había logrado convencerlos de hacer un pronunciamiento a favor de los insurgentes. Luego exhortaron a los habitantes de la ciudad a afiliarse a su causa, a lo que por lo pronto se opusieron, por lo que los cañones del castillo les echaron fuego, golpeando a algunos de los edificios principales y causando daño severo. Una bala de treinta libras penetró la pared de nuestro hotel, se llevó la pierna de un mesero desafortunado, que se estaba ocupando del aseo de los cuchillos, y cayó en el patio interno. El lugar es marcado por una embarradura de yeso fresco, justamente fuera de la puerta de nuestro dormitorio. La oficina del cónsul británico recibió una decoración similar. El gobernador de la ciudad no podía oponer resistencia, pero cortó el suministro de la isla y en tres o cuatro días Salcedo -quien se encontró sin parque y sin agua- se rindió con un discurso elegante, con lo que terminó la revolución.

Solamente nos podemos quedar poco tiempo en Veracruz, así que tengo que hacer mis observaciones de prisa, pues, cuando regresemos, el sol estará en el cenit, y la fiebre amarilla -que apenas se percibe ahora- habrá llegado para quedarse durante el verano. Bajo estas circunstancias, se le recomienda al extranjero no aclimatado que se quede acostado en una habitación fresca, fumando un puro y leyendo una novela, más que ir en búsqueda de información útil.

Hay calles con bonitas casas españolas, construidas de roca de coral blanco de los arrecifes cerca de la costa, pero están enmohecidas y con un aspecto deplorable. Fuera de las murallas está la alameda, y muy cerca se encuentra una hilera de casas, atizonadas, sin habitar, y en ruinas. Preguntamos “¿quién las construyó?”, "los españoles”, contestaron.

Aun ahora, cuando los "Nortes" soplan y la ciudad es relativamente salubre, Veracruz es un lugar melancólico, con un aspecto enfermizo. Pero su sobrenombre "la ciudad de los muertos" se debe realmente al tiempo de junio a octubre, pues esta estación representa un cúmulo de males. El sol está en su punto más alto, no hay ningún viento del norte que pueda limpiar el aire, y las pesadas lluvias tropicales -más de tres veces de lo que cae en Inglaterra durante todo el año- cae en una breve estación pluvial de cuatro meses. El agua se filtra a través de las colinas de arena y forman grandes lagunas de agua muerta. Surge una vegetación tropical rancia y pronto el aire se llena de vapores pestilentes. A eso hay que agregar que el agua es malsana y la ciudad se encuentra en un baño de arena, que mantiene una temperatura constante, acumulando calor durante el día y emitiéndolo durante la noche, así que la noche no alivia la pesadez sofocante del día. No deja de sorprender que el señor Bullock, el viajero británico, escuchara las campanas de la iglesia, doblando por los muertos sin interrupción, desde la madrugada hasta la noche, sentado en su habitación durante la estación de calor. Durante semanas enteras no me podía asomar en la calle sin avistar un sepelio.

Regresamos a la ciudad y mientras caminábamos observamos los zopilotes -grandes auras-con sus cabezas calvas y su plumaje negro y feo. Estaban sentados en filas compactas en las parapetas de las casas y de las iglesias; aparentemente tenían una preferencia por la 
cruz de la catedral, donde se asentaron, dos en los brazos de la cruz y algunos en la cúspide de la cruz. Cuando se tiraba algo de basura en la calle, bajaban con flojera por ella, uno tras otro. Su apariencia y su porte nos recordaba a los empleados de las funerarias, bajando del féretro en la puerta de la funeraria, al terminar la ceremonia. En toda América Latina estos pájaros son los principales basureros, y si alguien mata uno de ellos será severamente multado.

A esta hora de la tarde, apenas hay gente en la calle, con la excepción de un grupo de reos jalando sus cadenas pesadas, barriendo y reparando las calles. Ese es un castigo que tiene la simpatía de las autoridades mexicanas, ya que combina terror a los malhechores con ventajas a la comunidad y, aparentemente, no es considerado un problema de muchas consecuencias el poner al mismo nivel a todos los criminales, tanto a asesinos como a vagabundos.

En la puerta de entrada a la ciudad se encuentra un centinela -una de las cosas más curiosas que he visto en mi vida, en la forma de un soldado- un indígena cobrizo de la costa, vestido en unos trapos que una vez fueron un uniforme, descalzo y extremadamente mugroso, y armado con un impresionante viejo fusil de chispa. Su apariencia es bastante mala, y realmente es peor de lo que parece, pues no hay duda de que ha sido obligado a enlistarse en el ejército contra su voluntad y odia a los blancos y sus modos desde el fondo de su corazón. Es seguro que una vez que se le presente una oportunidad, desertará. Y aunque no será una pérdida muy grande al ejército, contribuirá con su granito al sentimiento de odio contra los blancos y los mestizos que se ha venido acumulando durante tantos años entre los indígenas. Pero a este punto volveremos más adelante.

Damos un paso fuera de la puerta y nos encontramos entre las colinas de arena que se extienden por millas y millas alrededor de Veracruz. Son montículos de arena movediza $\mathrm{y}$, aunque algunas de ellas miden cincuenta pies de altura, el feroz viento del norte las mueve. Los tejanos conocen bien estos vientos y los llaman "nortes". Llegan de la Bahía Hudson, en Canadá, al Golfo de México, bajando a través del continente de América del Norte, pasando por una planicie que no cuenta con una colina que pueda obstruir su curso, las Montañas Rocosas y las Montañas Alleghanies, que les forma una especie de túnel. Cuando sopla ferozmente el "Norte" es casi imposible mantenerse de pie en las calles de Vera Cruz, las embarcaciones jalan sus anclas o se escapan de sus amarres en el puerto mal protegido, y son empujadas hacia el mar - con suerte escapan de los arrecifes de coral y bancos de arena que adornan toda la costa. Fuera de la muralla crecen unos tantos arbustos, allí encontramos arbustos de nopal creciendo en grietas en las rocas y lugares estériles donde ninguna otra planta acepta crecer. Pero lo que llamó nuestra atención hacia los nopales fue el hecho de que estaban cubiertos de algo que parecía pequeños capullos blancos, que soltaban una gota de un líquido de color carmesí una vez apretados. Eso es el insecto de la cochinilla, pero solamente la variedad silvestre; la variedad fina que es utilizada para teñir y proviene de la provincia de Oaxaca, es cubierta solamente de un polvo harinoso. Allí los indígenas tienen grandes plantaciones de nopal y les riegan los insectos con inmenso cuidado, removiéndolos y subiéndolos a las montañas en canastas cuando empieza la estación de la lluvia, y cuando terminan las lluvias los vuelven a bajar de la misma manera.

El viernes 14 de marzo, a las tres de la mañana, ocupamos nuestros asientos en una diligencia fuerte y sólida construida en los Estados Unidos y con cupo para nueve en su interior, e iniciamos nuestro viaje siendo llevados a lo largo de las vías del ferrocarril cuya construcción fue iniciada con gran ímpetu hace algún tiempo, pero solamente avanzó quince kilómetros en el camino hacia la Capital, y luego nunca ha vuelto a moverse. 
Al amanecer habíamos abandonado las vías del tren y avanzamos traqueteando por una planicie con manchas de arena y escasamente cubierta con acacias, nopales, y otros tipos de cactáceas, begonias y las grandes euphorbias de árbol que ya habíamos conocido en Cuba, con sus ramas lisas y flores blancas. Finalmente alcanzamos la primera colina y empezamos suavemente el ascenso. El cambio fue maravilloso. En el momento de salir de la planicie nos encontramos en una selva tropical. Los árboles crecen apretadamente y el convólvulo ata sus ramos en una jungla impenetrable, mientras que helechos y trepadoras se convierten abajo en una masa densa. Aquí y allá alcanzamos la vista de una barranca honda que nos revela helechos grandes en forma de árboles, treinta pies de alto, quedándose cerca de la orilla de un arroyo de montaña y floreciendo en la sombra húmeda.

Las "granjas" indígenas se vuelven más frecuentes en la medida que ascendemos, y los habitantes -acuclillados en la tierra o reclinándose contra los postes de las puertascondescienden exactamente a echarnos un vistazo cuando pasamos, para luego regresar a sus meditaciones, y a sus cigarros, si es que tuviesen. Estas granjas no son más que chozas de caña con techo de hojas de palmera. Cerca de cada una hay un pequeño pedazo de tierra encerrado por medio de una barda de nopales, y adentro crecen plátanos, con sus hojas largas y suaves y con racimos pesados, la alimentación estable en la "tierra caliente".

Nuestro camino serpentea a través de los valles, paso tras paso, y de vez en cuando un tramo de zigzag nos lleva afuera de un valle para subir a un nivel más alto. El aire se vuelve más frío, el clima cambia rápidamente, y la tarde nos encuentra en la región de caña de azúcar y café. Pasamos al lado de inmensos campos de caña de azúcar, protegidos contra la incursión de campesinos y arrieros que pasan por allí por un denso cerco de espinosos arbustos de café. La caña es joven todavía, pero el arbusto de café, con sus flores blancas y brillantes, que parecen pequeñas estrellas, conforma un hermoso rasgo en el paisaje.

A la puesta del sol entramos matraqueando por las calles del pequeño pueblo de Córdova. Hay un ambiente tan cabalmente español en la plaza que podría bien ser un suburbio de la real Córdoba, si no fuera por los grupos de indígenas cobrizos en sus escasas ropas de algodón y sombreros con alas grandes, y la vestimenta de la gente blanca. Casas bajas encaladas con ventanas grandes que dan a la calle, protegidas por rejas pesadas de hierro, como jaulas, que les son tan familiares a los viajeros en el sur de Europa. Dentro de las rejas están las mujeres de la familia, fuera quedan paradas sus amistades masculinas, y el tiempo es dedicado al chisme. La pequeña lámpara humeante adentro nos permite una vista completa del interior. Cuatro paredes blancas, una mesa, unas pocas sillas con respaldo duro, una virgen o un santo con pintura y oropel, dos o tres grabados en color: rojo, azul y amarillo.

Unas pocas horas en oscuridad y alcanzamos Orizaba. Hoy por última vez hemos cambiado de clima y hemos alcanzado una región donde florece el tabaco a una altitud de 4000 pies sobre el nivel del mar. Pero no vemos nada de eso, pues arrancamos en la madrugada, antes de la luz del día, y cuando ya es posible discernir los objetos externos otra vez nos encontramos en una nueva región. Un valle pisado con ricas tierras aluviales que han bajado de las montañas que se elevan empinadamente a ambos lados, con sus cúspides cubiertas con nubes. Señales de una maravillosa fertilidad en los campos de maíz y centeno a lo largo de la carretera. El aire es caliente pero lleno de niebla que ya ha logrado penetrar nuestra ropa que se siente húmeda y pegajosa. "Esa es una tierra espléndida, señor", nos comentó un viejo mexicano después de voltearse en el asiento para inspeccionarnos esmeradamente. "Así parece", dije, "juzgando por la vista de los campos, pero es incómodamente húmedo ahora mismo". "Ahora mismo", dice el señor, haciendo eco de mis palabras, "siempre es húmedo aquí. Usted ve aquella neblina lluviosa. Es el 
chipi, chipi", "Nunca he escuchado el chipi chipi", "Pues, es la riqueza y la bendición del país. A veces no vemos el sol aquí durante semanas, y llueve un poco cada día. Pero, mira a aquellos campos, les sacamos tres cosechas cada año, mientras que en los campos justo arriba tenemos solamente una. Y es bueno para la salud. Mira a aquellos campesinos que trabajan allá. Cuando llegamos a los llanos usted va a ver la diferencia".

Los valles se vuelven más angostos a medida que avanzamos; y finalmente, cuando parecía que la carretera terminaría en una gran barranca empezamos a ascender por una carretera en zigzag. Pronto el aire se vuelve más transparente de nuevo, aparece el brillo del sol, hemos dejado atrás la niebla y nos encontramos entre colinas grandes y empinadas, cubiertas con la peculiar vegetación del altiplano: cactus, opundia y el maguey mexicano. El valle está lleno de un banco opaco de nubes blancas que esconde de nuestra vista los campos y las chozas. Ya hemos pasado la zona de humedad perpetua, cuya interminables nubes y aguaceros son causados por el estratum de aire caliente -cargado de agua evaporada del Golfo-, que se golpea contra las montañas para allí depositar una parte de los vapores acuíferos que contienen.

Los mismos procesos se pueden observar en casi cualquier región montañosa, pero raras veces a una escala tan grande como aquí, o con tan poca interrupción de parte de otros agentes. Pasamos el día de ayer en la tierra caliente, pero el día de hoy y de mañana será a través de la tierra templada y la tierra fría. Aquí un cambio de unos cientos de metros de pies de altitud lleva consigo un cambio de clima tan grande como varios grados de latitud, y en un solo día de viaje es posible descender de la región de nieve permanente hasta el mero corazón de la tierra tropical. Nuestro ascenso es más paulatino pero, aunque llevamos tres días en el camino, a veces casi no tenemos tiempo para notar las diferentes zonas de vegetación a través de las cuales pasamos antes de que cambien de nuevo.

Hay que decir un poco acerca de la formación del país, como se desprende ésta de un mapa de perfil, para que nuestro viaje de la costa a la Ciudad de México sea más comprensible. El interior de México consiste en una masa de rocas volcánicas que han sido dejadas a una gran altura sobre el nivel del mar. La planicie de México se encuentra a una altura de 8000 pies, y la planicie de Puebla a una altura de 9000 pies. Esta masa central se compone principalmente de un pórfido traquítico gris que en algunos lugares contiene ricas vetas de plata. Las cúspides de los cerros frecuentemente son coronadas con columnas de basalto, y abunda un amigdaloide suave y poroso en las orillas del Valle de México. Además se encuentra en abundancia rastros de actividades volcánicas más recientes, en la forma de numerosos cráteres extintos en la parte alta de la planicie e inmensos "pedregales" o campos de lava que todavía no tiene la edad necesaria para que su superficie se desintegre y se convierta en suelo. Aunque sí existen rocas sedimentarias en México, no son el rasgo predominante del país. Serranías de piedra caliza se encuentra en las inclinaciones de la gran masa volcánica hacia la costa, y más abajo, justo en la subida de la región costera plana y baja, encontramos yacimientos de piedra pómez. En nuestro camino de Vera Cruz encontramos piedra pómez inmediatamente al dejar atrás las planicies arenales, y unas pocas millas más adelante alcanzamos la piedra caliza, exactamente como está representada en el perfil del país desde Tampico hacia arriba, rumbo a San Luis Potosí, de acuerdo a Burckardt. Las planicies montañosas, tales como las planicies de México o Puebla, son hondonadas que son llenadas con depósitos terciarios que también constituyen su piso, y de nuevo son cubiertas de los yacimientos de aluvial que se acumulan constantemente.

Nuestro ascenso pesado por las faldas de la montaña nos ha dejado en un escenario nuevo. Todo el mundo sabe cómo se acomoda la nieve en los valles en los Alpes, formando una planicie que se inclina gradualmente hacia la salida. Imagínese un valle que mide diez 
millas a través, con una planicie inclinada de esta manera, pero no de nieve sino de tierra. No ha llovido durante meses y la superficie de la tierra es árida y cuarteada por todos lados. Apenas se ve un solo árbol, con la excepción de trozos de madera en las laderas de las montañas a varias millas de distancia -ninguna vegetación, pero penachos de pasto tosco entre los cuales vagaban rebaños de ganado de apariencia desconsolada. Los vaqueros iban a medio galope siguiéndolos en sus caballos flacos con sus lazos colgando en roscas sobre su brazo izquierdo, de vez en cuando llamando a alguna vaca contumaz que intenta abandonar el rebaño arrojando el lazo alrededor de sus cuernos o dejándolo caer frente a ella, de manera que corre y se mete dentro del lazo que levanta con un jalón, rodeando sus piernas traseras como pisando adentro. Pero los pobres animales son demasiado sedientos y desanimados como para poner resistencia, y tan sólo al primer toque del lazo regresan a su lugar.

Del pórfido descompuesto baja de las montañas a los valles sodio de carbonato en solución, y gran parte de eso es convertida en nitrato por la sustancia orgánica en el suelo y forma una corteza blanca en la tierra. Más del carbonato de sodio, mezclada en diferentes proporciones con la sal común, se filtra continuamente en las corrientes o se filtra en la tierra y allí se cristaliza. Es por eso que no se ve ningún campo y la tierra no sirve para otra cosa que pastizales. Pero, dicen nuestros amigos en la diligencia, cuando empiezan las lluvias en pocos meses este lúgubre desierto será una pradera frondosa y habrá miles de cabezas de ganado, pues en su gran mayoría está disperso en las regiones más bajas de la tierra templada, donde hay pasto y agua.

Junto con mi acompañante trepamos al techo de la diligencia para reconocer el terreno. El gran volcán de Orizaba se nos había escondido desde aquella mañana cuando lo vimos desde muy lejos en el mar, pero ahora se levanta a nuestra izquierda, la mitad superior siendo a medias cubierta de una nieve tan blanca que deslumbra - un cono regular, pues de este lado no es posible ver el cráter. Se ve como si uno pudiera caminar media milla y luego subir directamente a la cúspide, pero está todavía a treinta millas de aquí. El aire es tan caliente como si saliera de un horno y como avanzamos por la carretera, las nubes de polvo se vuelven sofocantes. Avanzamos a pleno galope, metiéndonos en todos los hoyos posibles, cruzando las trincheras dejadas por los cursos de agua del año pasado, hasta que empezamos a pensar que tiene que terminar en un choque general. Poco antes de llegar a la Capital, logramos entender mejor las carreteras y los cocheros mexicanos.

Enfrente de nosotros y detrás se extendían grandes lagos, alcanzando de un lado del valle al otro, pero el lago detrás de nosotros nos seguía tan fielmente como el lago que en frente residía. Fue solamente el espejismo que tanto atormenta a los viajeros en estos valles chamuscados, durante todos los ocho largos meses de la estación de la sequía. Al principio parecía hermoso, luego monótono, y finalmente, mucho antes de terminar el día, lo odiaba con un odio extremadamente cordial y sincero.

Pronto una nueva apariencia captó nuestra atención. Primero, nubes de polvo que paulatinamente asumieron una forma definitiva y bien definida, y se convirtieron en columnas inmensas, girando rápidamente alrededor de sí mismas y moviéndose lentamente por la planicie. En un lugar, donde varios pequeños valles desembocaron en el nuestro, estas columnas de arena, algunas pequeñas y otras grandes, se pavonearon en docenas, viéndose como el genio inmediatamente después de que el pescador lo hubiera dejado salir de la botella, y las vimos con asombro empezar a formarse como un gigante de un tamaño monstruoso. En efecto, estoy seguro de que el cuentista tenía en mente exactamente este tipo de columnas de arena cuando escribió su hermoso cuento. En el Oriente se pueden ver miles de éstas. Cuando avanzaron absorbieron pequeñas piedras, polvo y hojas, y 
nuestro cochero declaró que se habían visto quitarles el techo a casas y llevarse al aire rebaños enteros de borregos, "pero las que vemos aquí no son gran cosa", dijo. Estimamos el tamaño de la más grande como de cien pies de altura y treinta pies en diámetro, y esta misma columna, que de pura casualidad se dirigía hacia una casa, definitivamente perdió la contienda y sus extremidades inferiores fueron hechas pedazos.

Cuando el sol se vuelve caliente, la tierra desnuda calienta el aire que se encuentra sobre ella tanto que nace una corriente hacia arriba desde toda la superficie del valle y, para ocupar el espacio del aire desaparecido, los pequeños valles y barrancas que desembocan en él vierte cada uno una corriente de aire fresco, y cuando dos de estas corrientes, moviéndose en direcciones diferentes, chocan resulta un pequeño remolino y se manifiesta como una columna de arena. El "molino de viento" del cochero, como lo llamaba él, puede bien haber sucedido, solamente que debe de haber sido un molino mucho más grande, causado por corrientes atmosféricas más grandes y no por los pequeños movimientos que presenciamos.

Parece que no hay un solo pueblo en la planicie y los únicos edificios que vemos a millas a la redonda son las chozas de los pastores: casas de piedra, con techo plano, obscuras por dentro y en su apariencia muy poco acogedores, y los grandes corrales de ganado que parecen absurdamente demasiado grandes para el ganado que está a la vista, pero en dos o tres meses lloverá y entonces la tierra será cubierta de pasto exuberante y los corrales serán atascados de ganado cada noche. El espejismo desaparecerá cuando llega la auténtica agua, ya no se verán polvos y columnas de arena, y los nueve animales del equipo de la diligencia, revolcándose, chapoteando y pateando, apenas podrán evitar que la diligencia se hunda inextricablemente en el lodo. Así sigue hasta octubre, y luego la estación de lluvia -“la estación de las aguas"- terminará, y las cosas serán otra vez como son ahora.

En el curso acostumbrado de viajes a la Capital, la segunda noche se pasaría en Puebla. Esta es la segunda ciudad de la República, con alrededor de 70000 habitantes. Como estaba en aquel momento sublevada, y sitiada por el Presidente y su ejército, nos desviamos hacia el norte con la intención de dormir unas horas en Huamantla, un lugar con una pésima reputación de ladrones y gentuza, y alrededor de las diez de la noche entramos en el patio de una posada de apariencia lúgubre. Cuando nos apeamos estaban parados tres o cuatro personas sucias, enrollados en sus sarapes - grandes cobijas de lana, la vestimenta universal de los mexicanos del altiplano-. Un extremo del sarape se echa atravesado de hombro a hombro, escondiendo la parte inferior de sus caras, y los sombreros mexicanos de alas grandes estaban inclinados hacia abajo sobre sus ojos. No nos cayeron bien en absoluto, especialmente porque estaban mirándonos a nosotros y a nuestro equipaje, mientras entramos a la posada. Unos minutos más tarde regresamos al patio para terminar nuestra inspección ocular de ellos, pero ya no estaban.

Un grupo de españoles y mexicanos se encontraba alrededor de la otra mesa en la sala cuando entramos en desfile, y cuando habíamos acabado con la parte más urgente de nuestra hambre, empezamos a comparar notas con ellos. "¿Tuvieron un viaje agradable de México?". Todos contestaron al mismo tiempo, encantados de encontrar una audiencia a la cual podían contar sus penas, como siempre es el caso de los hombres bajo tales circunstancias. Aparentemente habían llegado a Huamantla una hora o dos antes de nosotros, y para su grata sorpresa no se había presentado ningún asaltante. Pero entre las afueras del pueblo y la posada fueron cortadas las cuerdas de la diligencia, y cada pieza de equipaje había desaparecido. En la entrada a la posada bajaron y descubrieron su pérdida. Se lanzaron contra el administrador de la compañía de diligencias, el estaba lleno de simpatía por ellos pero no podía ofrecer ninguna consolación más concreta. Declararon 
que el cochero debía de haber sido cómplice, y se llamó al cochero para que se pudieran desquitar con él. Él apareció con la boca llena de frijol y les contó, en cuanto pudo hablar, que deberían de estar agradecidos, puesto que habían tenido tanta suerte, y luego volvió a su comida, echándoles una mirada llena de un disgusto infinito. Ellos siguieron su ejemplo y aparentemente encontraron su consuelo en la comida caliente y en el vino catalán. Fue maravilloso escuchar de todas las cosas finas que estaban en las bolsas perdidas -anillos, relojes de oro, rollos de dólares, documentos de máxima importancia-. Temo que los latinoamericanos no siempre tengan en la más alta estima la verdad.

De veras, estos señores habían tenido suerte, como dijo el cochero, pues la última diligencia de Veracruz, con nuestros conocidos del vapor, habían parado justo fuera de este mismo pueblo de Huamantla, ya que lo dejaron antes de la luz del día en la madrugada. Había solamente tres asaltantes, pero les habían robado tan a fondo a los desafortunados viajeros, como si lo hubieran hecho treinta ladrones. Eso sonaba muy bien como un cuento, pero de ninguna manera fue satisfactorio a viajeros que el siguiente día tomarían el mismo camino. Y en la habitación desagradable en donde nuestras camas estaban formadas en una sola línea, nosotros, los nueve pasajeros de arriba, celebramos un consejo de guerra, parados, como los senadores de McCauley, y allá decidimos de una manera sumamente cristiana nuestra respuesta -que cuando los tres se llegaran hasta nosotros y el cañón de la inevitable escopeta fuera metido por la ventana de la diligencia, entonces bajaríamos dócilmente y al comando "boca abajo" nos humillaríamos con las narices en el lodo, y nos dejaríamos tranquilamente robar-. Cuando de esta manera ya por adelantado habíamos decidido, de acuerdo a la etiqueta de la carretera, si lucharíamos o nos rendiríamos, bajo el cansancio de la larga jornada, todos nos dormimos profundamente en un instante.

Parecía que casi inmediatamente después nos despertó el hombre más sucio que jamás había visto, sacudiéndonos hasta que estuviéramos despiertos. Nos lavamos en las ollas acostumbradas a la luz de una lámpara real española, con un pico, exactamente como los que los romanos habían utilizado en Pompeya, solamente que esta era de latón y no de bronce.

Con nuestros ojos todavía medio cerrados entramos a la cocina para ingerir nuestro chocolate matutino y pedimos la cuenta. ¡Qué cuenta! Uno de nosotros, un español corpulento, llamó al propietario y lo regañó en un discurso peculiar. El "patrón” eliminó de su cara cualquier rastro de expresión, se rascó la cabeza a través de su gorro de dormir grasoso, escuchando pacientemente. El hombre corpulento se volvía a cada rato más furioso y terminó en un clímax: "si nos encontramos con los asaltantes", dijo, enrollándose en su capa grande, "les tenemos que decir que ya hemos pasado por las manos de su excelencia y que no nos queda nada". El patrón se inclinó seriamente y nos acompañó a la diligencia, deseándonos un feliz viaje sin "novedades". Una "novedad" significa en países hispanohablantes una mala fortuna.

No hubo "novedad" alguna aunque, cuando vimos por la ventana en la madrugada y vislumbramos a tres hombres con mosquetes siguiéndonos a corta distancia, pensamos que ya habíamos llegado a nuestro fin, y echamos nuestros relojes y otros valores en las botas, debajo de los asientos y a través de ranuras en el relleno de la diligencia; pero los tres hombres no se acercaron más y suponíamos que debía haber sido una escolta de soldados. Lo difícil fue recuperar nuestras objetos valiosos cuando se había levantado el sol, tan bien los habíamos escondido.

Posteriormente nos contaron de una peculiaridad que distingue a los ladrones de Huamantla. Parece que nada menos que el párroco solía guiar a sus parroquianos en la acción, igual que el sacerdote de Cornwall en tiempos pasados cuando un barco se estrelló 
contra los arrecifes. De la suerte de su reverencia después no tengo noticias. Lo más probable es que sigue siendo párroco y continúa en su doble profesión, a menos que alguien lo haya matado. Estoy pensando si es un sacrilegio matar a un sacerdote que es al mismo tiempo un asaltante, así como solía ser un sacrilegio matar a un obispo en el campo de batalla.

Por fin nos encontramos en el altiplano de México, la región en la cual por lo menos tres civilizaciones han decidido establecerse, haciéndoles caso omiso a las tierras fértiles de abajo. Una curva aguda en la carretera nos lleva adentro de la planicie, y luego a la izquierda tenemos dos montañas cubiertas de nieve que se encuentran en las orillas del Valle de México, Popocatepetl e Iztaccíhuatl, famosas en todos los libros mexicanos. Como ayer en el caso de Orizaba, parecen levantarse de la planicie cerca de nosotros, y desde el valle entre las dos montañas sopla un viento en nuestro encuentro tan helado que temblamos lastimeramente y nuestros dientes se ponen a resonar, no obstante que las ventanas están cerradas y tenemos a nuestras chamarras abotonadas al cuello, hasta que salgamos del aire frío. Luego vuelve el brillo caliente del sol y el polvo.

Ansioso por asegurarse de que realmente nos encontramos en la tierra de la civilización de los aztecas, el Señor Christie se apea de la diligencia e inspecciona durante unos minutos la tierra al lado de la carretera, después regresa en triunfo con una punta de flecha rota de obsidiana. Un canal profundo cavado por el curso del agua nos proporciona una primera idea acerca de la profundidad del suelo; pues alguna vez estas planicies no eran más que unas profundas hondonadas entre las montañas que la lluvia y la nieve derretida han llenado, cargando hacia abajo fragmentos de pórfido y basalto - parcialmente en su estado original y parcialmente descompuesto - conformándolos en planicies. Para no decir nada de las dos montañas frente a nosotros, detrás de nosotros hay una colina de tufo volcánico rojo y más adelante nuestro camino pasa por el campo de lava al pie del pequeño volcán de Santa Bárbara. Pero, ahora me estoy adelantando.

Aquí hay gente, comunidad tras comunidad; y entre las comunidades hay grandes plantaciones de maíz y maguey, pues ésa es la tierra del pulque, "los llanos del Apan". Es el Agave Americano, el mismo maguey que es tan común en el sur de Europa donde verdaderamente florece, y que crece en nuestros jardines y que solía tener la reputación de florecer cada cien años. No exagero al decir que vimos cientos de miles de magueyes aquel día, plantados en largas hileras derechas. Entre ellos iban los "tlachiqueros" mexicanos, cada quien con su piel de cochino sobre la espalda y su calabaza larga, ordeñando las plantas maduras.

Los finos edificios de las haciendas, y en particular las iglesias, producen un fuerte contraste con las casas en general, todas de un solo piso, construidas de adobe (ladrillos de lodo, secados al sol), con techos planos de arena y lima sostenida sobre vigas de madera, y un piso de lodo también, todas las casas oscuras, mugrosas e incómodas. Hay aún casas enteras construidas del universalmente presente maguey. Las pencas de magueyes silvestres que han podido florecer son metidas en la tierra, una al lado de la otra, y piezas de hojas les son amarradas por fuera con fibra de maguey. Estas hojas cortadas son colocadas como tejas para formar un techo, y fijadas con las espinas que crecen en sus extremos. Pictórico y barato, aunque no muy cómodo, pues ya nos encontramos en "tierra fría" y durante el invierno las mañanas y las noches frecuentemente son amargamente frías.

Pero las iglesias. ¿Es posible que pertenezcan a aquellas pequeñas y miserables chozas? Como señala nuestro chofer Sam el Negro, un esclavo de Texas que se ha escapado, parece como que los habitantes pudieran demoler sus casas en la noche y acomodarse con toda su familia en sus iglesias. Pensamos en el señor Ruskin que ha expresado un pío deseo de que todo el dinero y energía que Inglaterra ha gastado en la construcción de ferrocarriles, se 
pudiera invertir en la construcción de iglesias. Ojalá que hubiera estado aquí con nosotros para ver sus principios realizados.

En mi tiempo he viajado por muchas carreteras rudas, pero nunca en mi vida por una carretera como ésta. Mi compañero se negó durante algún tiempo a otorgarle el premio de maldad a nuestro viaje. Pero en el mero momento que estábamos discutiendo la cuestión, alcanzamos un paso donde el camino consistía en una serie de escalones de casi un pie de profundidad, por los cuales bajamos a un trote vivo, agarrándonos para salvar la vida, aterrorizados por la idea de que la siguiente sacudida pudiera sacarnos los brazos de sus troncos y escuchando claramente los gritos de los pasajeros adentro pidiendo piedad cuando sus cabezas eran tiradas contra el techo que las devolvía a sus asientos. Con el cuerpo entero adolorido, llegamos de nuevo a terreno plano, y el señor Christie retiró sus pretensiones, admitiendo que ninguna carretera en ninguna parte del mundo podía posiblemente ser peor que las carreteras mexicanas, una opinión que posteriores experiencias servirían para confirmar.

Era todo un evento cada vez que cambiábamos de caballos para volver a iniciar nuestro viaje. Nueve caballos y mulas medio domados, en un estado furioso de excitación, habían sido enganchados a nuestra pesada máquina; los ayudantes los soltaron y se fueron, pateando, corcoveando, encabritándose, mordiendo y rugiendo, metiéndose en cada surco y en cada arroyo que parecían más bien las trinchas que cavan para los tubos de gas en las calles en Londres, con las ruedas de un lado en un muro de piedra y en una zanja al otro lado, y Black Sam, reclinándose con sus pies contra la tabla de pie, esperando en perfecta tranquilidad hasta que los animales hubieran desechado la energía sobrante y pudiera volver a controlarlos. Todo el tiempo estábamos al borde de algún terrible accidente, y cada vez volvíamos a salvarnos exactamente. En el último tramo antes de alcanzar Otumba, un pequeño pillo moreno atravesó la carretera justo en frente de nosotros. No sé de qué manera logró Sam frenar la diligencia, aunque de verdad sus brazos eran del tamaño del muslo de un hombre ordinario. Pero lo logró y sacaron al niño ileso de entre las patas de los caballos.

En la posada donde paramos para desayunar conocimos por primera vez a aquellas grandiosas instituciones mexicanas -la tortilla y el pulque-. El pulque se producía a una escala mayor en un edificio vecino. Los tinacos eran hechos de pieles de vaca (con el pelo hacia dentro), sostenidos por un esqueleto de palos. Y los tinacos contenían pulque a todos los diferentes estadios de elaboración, empezando con la dulce aguamiel, el jugo fresco del maguey, y después en diversos grados de fermentación, hasta alcanzar la madre pulque, el pulque madre del cual un poco es utilizado como levadura para iniciar la fermentación, y cuyo olor se encuentra entre los de una planta de gas y una alcantarilla. El pulque, al ser bebido, parece leche y agua, y tiene un olor y un sabor suave de huevos podridos. Las tortillas son como tortas de avena, pero son hechas de harina de maíz, no son quebradizas y frágiles sino suaves y corredizas. Durante un día o dos nos parecieron horribles, pero después las pudimos tolerar; más tarde llegamos a disfrutarlas, y al momento de salir del país estábamos pensando, ¿cómo iríamos a vivir sin ellas? 